Document downloaded from:

http://hdl.handle.net/10251/66162

This paper must be cited as:

Sachse, A.; Wuttke, C.; Díaz Morales, UM.; Oberson De Souza, M. (2015). Mesoporous Y zeolite through ionic liquid based surfactant templating. Microporous and Mesoporous Materials. 217:81-86. doi:10.1016/j.micromeso.2015.05.049.

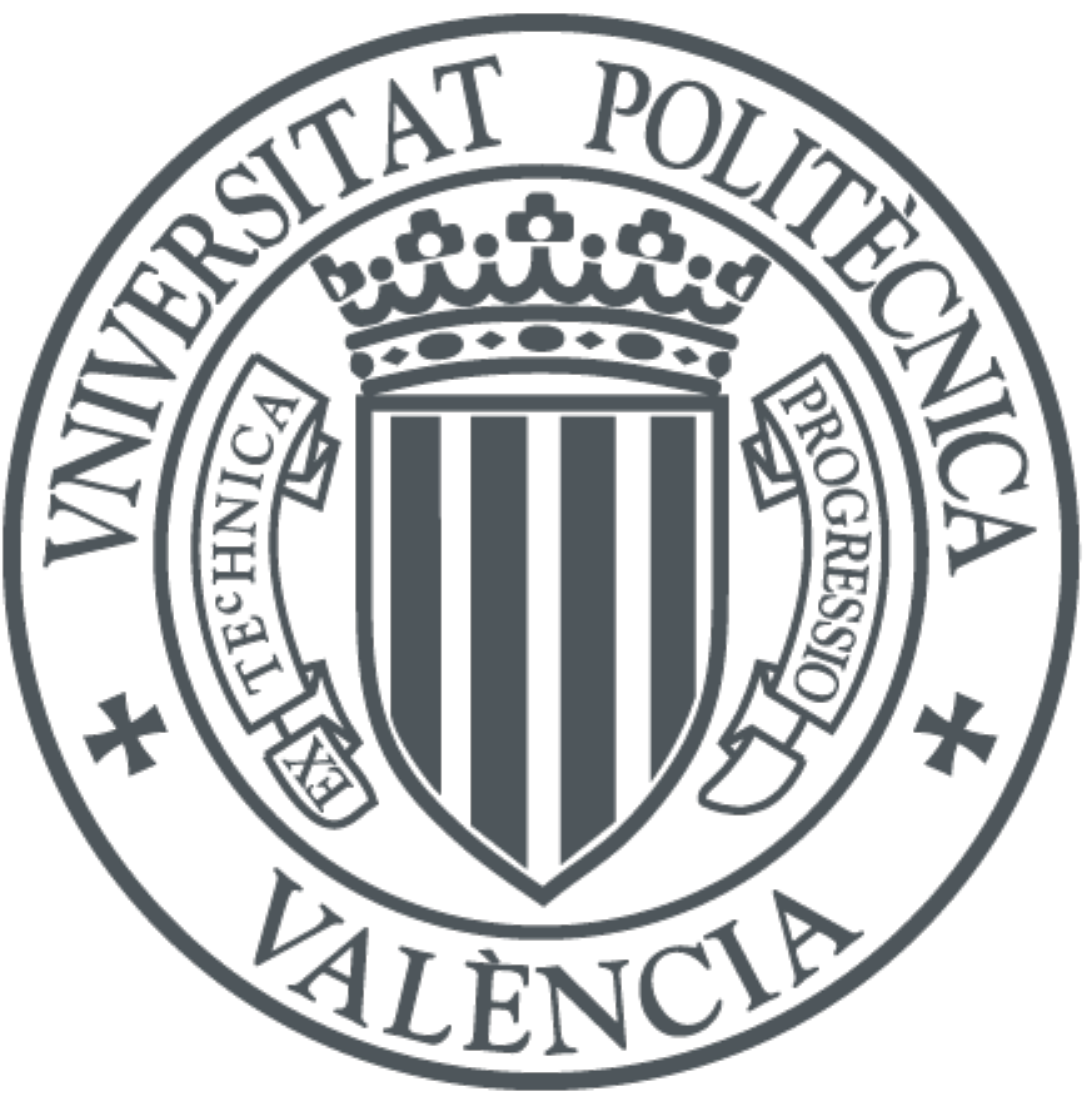

The final publication is available at

http://dx.doi.org/10.1016/j.micromeso.2015.05.049

Copyright Elsevier

Additional Information 


\title{
Mesoporous Y zeolite through ionic liquid based surfactant templating
}

\author{
Alexander Sachse ${ }^{\text {a, }{ }^{*} \text {, Caroline Wuttke }}{ }^{\text {a, } 1}$, Urbano Díaz ${ }^{\text {b, } 2}$, Michele Oberson de Souza ${ }^{\text {a, } 1}$ \\ a Institute of Chemistry, UFRGS, Av. Bento Gonçalves 9500, 91501-907 Porto Alegre, Box 15003, Brazil \\ ${ }^{\mathrm{b}}$ Instituto de Tecnología Química, UPV-CSIC, Universidad Politecnica de Valencia, Avenida de los Naranjos s/n, 46022 Valencia, Spain
}

\section{a $\mathrm{r}$ t i c l e i n f o}

\section{Article history:}

Received 6 February 2015

Received in revised form

22 May 2015

Accepted 26 May 2015

Available online 16 June 2015

\section{Keywords:}

Mesoporous zeolites

Surfactant templating

Recrystallization

Hierarchical porosity

Ionic liquids

\begin{abstract}
$a b s t r a c t$
New surfactant molecules based on ionic liquids, such as $\left[\mathrm{C}_{16} \mathrm{MIm}\right] \mathrm{Cl}$ and $\left[\mathrm{C}_{16} \mathrm{MPy}\right] \mathrm{Cl}$ were employed in the rearrangement of $\mathrm{Y}$ zeolite to introduce mesopores of different morphologies. We evidence that the templating efficiency of these ionic liquids is identical as for the classically used ammonium based surfactant (CTAC) in the synthesis of siliceous MCM-41. Yet, their templating behavior differs importantly when used in the surfactant templating approach to produce mesoporous Y zeolite. This finding indicates that the micellization ability of these surfactants within the zeolite confined spaces differs to the one in solution and hence has a major impact on the textural properties of the final zeolite phase. Hierarchical porous zeolite $\mathrm{Y}$ with novel textural properties could be disclosed.
\end{abstract}

\section{Introduction}

Zeolites account for massive use in industry thanks to their excellent catalytic properties permitting in many cases shape selectivity in important large-scale applications. Yet, this particularly interesting materials class presents major drawbacks based on the sole presence of micropores causing sever mass transfer limitations. To remedy this inconvenient purely mesoporous materials (such as $\mathrm{Al}-\mathrm{MCM}-41$ with $\mathrm{Si} / \mathrm{Al}$ ratios comparable to those in zeolites) were developed, presenting high accessibility to active sites and low diffusion limitations [1]. However, their catalytic activity remains low when compared to the one of zeolites [2,3]. It is hence a current quest to combine the advantages of these two material classes, i.e. generating mesoporosity within zeolite frameworks. It has indeed been proven that the introduction of mesopores within microporous zeolite structures allows for superior mass transfer properties [4e8] and higher accessibility to active sites $[9,10]$. Additionally, tailoring pore size of the introduced mesoporosity presents in many cases an important effect in catalysis [10e13].

Several strategies for the achievement of hierarchical porous zeolites are disclosed in the literature and summarized in numerous

\footnotetext{
* Corresponding author. Tel.: p55 513308 7238; fax: p55 5133087304.

E-mail address: alexander.sachse@ufrgs.br (A. Sachse).

1 Tel.: p55 513308 7238; fax: p55 5133087304.

2 Tel.: p34 963877811; fax: p34 963877809.
}

review articles [15e21]. The majority of available techniques rely on either destructive or constructive methods. Destructive approaches, also known as top-down strategies, are mainly related to dealumination [22e26] or desilication [27]. The major inconvenience of these techniques is the formation of an arbitrary mesoporous network that forms mainly as internal and inaccessible cavities. On the contrary, constructive approaches (so called bottomeup strategies) are based on the formation of the hierarchical porous zeolites employing soft [28e31] or hard [32e35] templates and permit in many cases the introduction of tailored mesoporosity. An alternative strategy is the surfactant templating approach, which allows to impart tailored mesoporosity within given zeolite structures. Different theories exist to explain the fundamental mechanism of the surfactant templating process, that are either based on zeolite recrystallization [36e39] or rearrangement [40,41]. The recrystallization mechanism is believed to rely on a preliminary partial destruction and dissolution of the zeolite framework under basic conditions followed by the re-assembly in the presence of surfactants. On the other hand, the zeolite rearrangement mechanism is conceived to take place through a spontaneous assembly of surfactants within the zeolite cavities that rearrange the zeolite phase without the occurrence of the dissolution event.

To date the only supramolecular templating agents described in the surfactant templating approach to achieve mesoporous zeolites are ammonium based salts (i.e. $\mathrm{C}_{\mathrm{n}} \mathrm{H}_{2 \mathrm{np1}}\left(\mathrm{CH}_{3}\right)_{3} \mathrm{NBr}, \mathrm{n} 1 / 4$ 8e18). This process has proven to be an efficient strategy for the introduction of 
ordered mesopores in various zeolites, such as Y [42], MOR [43], BEA [44] and ZSM-5 [45].

Ionic liquids have recently emerged as a new molecule class with important properties especially as green solvents, electrolytes and catalysts [46]. Furthermore, the use of ionic liquids has lately attracted a great deal of attention for the design of porous materials [47e50]. In fact, the imidazolium headgroup has been described to present superior templating properties in the hydrothermal synthesis of MCM-41, compared to commonly used ammonium based surfactants, figuring identical chain lengths (i.e. CTAB or CTAC) [51]. Furthermore, ionic liquids have very recently allowed for the obtention of mesoporous zeolites by a simple bottomeup approach [52].

Herein we describe the templating behavior of ammonium, imidazolium and pyridinium based surfactants with identical chain lengths in the synthesis of siliceous MCM-41 and in the achievement of mesoporous $\mathrm{Y}$ zeolite through surfactant templating process.

\section{Experimental section}

\subsection{Synthesis of $M C M-41$}

In a typical synthesis the surfactant $(8.2 \mathrm{mmol})$ was dissolved in distilled water $(18 \mathrm{~mL})$ and absolute ethanol $(204 \mathrm{~mL})$. To this solution was added TEOS (11.21 g, SigmaeAldrich, 98\%). Additionally, $\mathrm{NH}_{4} \mathrm{OH}$ ( $66.2 \mathrm{~mL}$ of $25 \%$ solution) was slowly added under vigorous stirring at RT. The molar composition of the mixture was $1 \mathrm{SiO}_{2}$ : $141 \mathrm{H}_{2} \mathrm{O}: 2.8 \mathrm{NH}_{3}: 0.082$ Surfactant. After complete addition of $\mathrm{NH}_{4} \mathrm{OH}$ the mixture was stirred for three additional hours. Finally the mixture was filtered and the residue was washed with distilled water until neutral $\mathrm{pH}$. The solid was dried at $80^{\circ} \mathrm{C}$ for $24 \mathrm{~h}$ and additionally calcined at $550^{\circ} \mathrm{C}$ for $8 \mathrm{~h}$ under air using a heating rate of $2{ }^{\circ} \mathrm{C} / \mathrm{min}$.

\subsection{Surfactant templating of $Y$ zeolite}

In a typical synthesis the surfactant $(0.911 \mathrm{mmol})$ was dissolved in an aqueous $\mathrm{NaOH}$ solution $(0.09 \mathrm{M}, 20 \mathrm{~mL})$ at RT. After complete dissolution, $0.67 \mathrm{~g}$ of commercial HY zeolite (Zeolyst, CBV720, Si/ $\mathrm{Al} 1 / 4$ 15) was added and stirred for $20 \mathrm{~min}$. The molar composition of the mixture was: $1 \mathrm{HY}: 0.08 \mathrm{Na}_{2} \mathrm{O}: 100 \mathrm{H}_{2} \mathrm{O}: 0.082$ Surfactant. The obtained suspension was transferred to a Teflon-lined stainless steel autoclave and hydrothermally treated for $20 \mathrm{~h}$ at $150{ }^{\circ} \mathrm{C}$ under autogenous pressure. The autoclave was cooled to RT and the mixture was filtered and the residual solid was washed with $200 \mathrm{~mL}$ of distilled water. The solid was dried at $80^{\circ} \mathrm{C}$ for $24 \mathrm{~h}$ and then calcined at $550{ }^{\circ} \mathrm{C}$ for $8 \mathrm{~h}$ under air using a heating rate of $2{ }^{\circ} \mathrm{C} /$ $\min$.

\subsection{Synthesis of the templating agents}

Cetyltrimethylammonium chloride (CTAC) was purchased from SigmaeAldrich (98\%). Cetyl-1-methylimidazolium chloride $\left(\left[\mathrm{C}_{16} \mathrm{MIm}\right] \mathrm{Cl}\right)$ was synthetized by combining $0.85 \mathrm{~mol}$ of $1^{-}$ methylimidazole (SigmaeAldrich, 99\%) with 0.85 mol of hexadecyl chloride (SigmaeAldrich, 95\%) in a round bottom flask with magnetic stirrer. The mixture was vigorously stirred at $115^{\circ} \mathrm{C}$ for $48 \mathrm{~h}$. The flask was cooled to room temperature and the residue was washed with ethyl acetate and dried under vacuum. Cetyl-4picolinium chloride $\left(\left[\mathrm{C}_{16} \mathrm{MPy}\right] \mathrm{Cl}\right)$ was synthetized by mixing $0.1 \mathrm{~mol}$ of 4-methylpyridine (SigmaeAldrich, $98 \%$ ) with $0.1 \mathrm{~mol}$ of hexadecyl chloride in $100 \mathrm{~mL}$ toluene in a round bottom flask with magnetic stirring. The mixture was vigorously stirred under reflux for $72 \mathrm{~h}$. The flask was cooled to RT and the solvent was removed in vacuum. The residue was washed with ethyl acetate and dried under vacuum.

\subsection{Characterization}

Nitrogen adsorptionedesorption isotherms were measured at $77 \mathrm{~K}$ using a TRISTAR II Micrometrics volumetric adsorption analyzer. Before the measurements, samples were outgassed for $16 \mathrm{~h}$ at $573 \mathrm{~K}$. The BrunauereEmmetteTeller (BET) equation [53] was used to calculate the apparent surface area from the adsorption data obtained at $\mathrm{p} / \mathrm{p}_{0}$ between 0.05 and 0.3 considering the Rouquerol law to determine the highest relative pressure to use in the BET method [54]. The pore size distribution was calculated by the BarretteJoynereHalenda (BJH) method using the adsorption branch [53]. Microporous volumes were calculated using the corrected t-plot method developed by Galarneau et al. [56] X-ray diffraction (XRD) patterns were recorded with a Goniometer type D-500 Simens equipped with CuKa radiation (40 kV, $40 \mathrm{~mA})$. Low Resolution Transition Electron Microscopy (LR-TEM) was performed on a Libra Zeiss electron microscope at $120 \mathrm{kV}$. Samples were embedded in a polymer resin and cut into thin slices by ultramicrotomy. High Resolution Transition Electron Microscopy (HRTEM) was performed on a JEOL JEM-2100 at $200 \mathrm{kV}$. Scanning Electron Microscopy (SEM) images were recorded on an EVO Zeiss@50 Series electron microscope equipped with an EDX detector. The amount and distribution of the acid sites of the materials was monitored by temperature-programmed desorption of $\mathrm{NH}_{3}$ (TPD-NH ${ }_{3}$ ) using a Micromeritics apparatus Model TPD/TPR 2900. The type of acidity (Lewis and/or Brønsted) of the sample was tested by pyridine adsorption followed by Fourier Transform Infra Read Spectroscopy. Infrared (IR) experiments were performed in a Nicolet 710 Fourier transform IR (FTIR) spectrometer using vacuum cells. After the $\sim 10 \mathrm{mg} \mathrm{cm}^{-2}$ wafers were degassed overnight under vacuum $\left(10^{-3} \mathrm{~Pa}\right)$ at $673 \mathrm{~K}$, the base spectra were recorded at room temperature. For acidity measurements, pyridine $(6 \times 102 \mathrm{~Pa})$ was admitted. After equilibration, the samples were outgassed for $1 \mathrm{~h}$ at increasing temperatures (423/523/623 K). After each desorption step, the spectrum was recorded at room temperature and the background subtracted.

\section{Results and discussion}

\subsection{Synthesis of siliceous MCM-41 using ionic liquid based surfactants}

Ionic liquids of identical chain length of the alkyl substituent, based on imidazolium and pyridinium salts $\left(\left[\mathrm{C}_{16} \mathrm{MIm}\right] \mathrm{Cl}\right.$ and $\left.\left[\mathrm{C}_{16} \mathrm{MPy}\right] \mathrm{Cl}\right)$ were employed as surfactants in the synthesis of siliceous MCM-41 and their templating efficiency was compared to the one of CTAC, an ammonium salt which is the typically used surfactant in this synthesis (Fig. 1). The obtained calcined materials

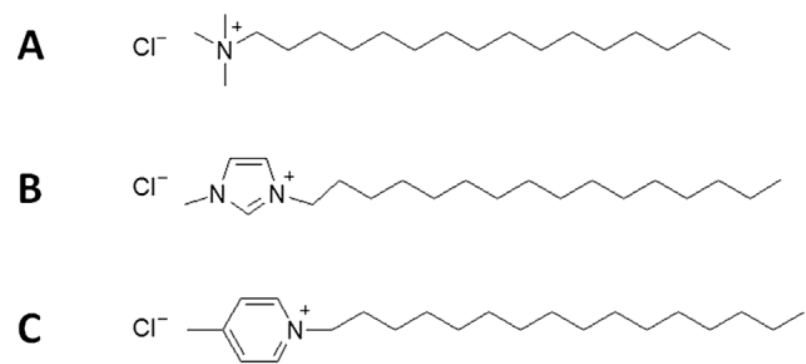

Fig. 1. Chemical structure of $\mathrm{CTAC}(\mathrm{A}),\left[\mathrm{C}_{16} \mathrm{MIm}\right] \mathrm{Cl}(\mathrm{B})$ and $\left[\mathrm{C}_{16} \mathrm{MPy}\right] \mathrm{Cl}(\mathrm{C})$ 
present type IV nitrogen adsorption and desorption isotherms with a steep increase of nitrogen in the relative pressure range of $\mathrm{p} /$ $\mathrm{p}_{0} 1 / 40.2 \mathrm{e} 0.4$ characteristic for mesoporous materials with very narrow pore size distributions. For all of the materials very similar isotherm shapes were obtained and materials figure specific surface areas of close to $1000 \mathrm{~m}^{2} \mathrm{~g}^{-1}$ and mesoporous volumes of $0.85 \mathrm{~mL} \mathrm{~g}^{-1}$ (Fig. 2A). Furthermore, the low angle XRD patterns present for the three samples characteristic peaks at 2.6, 4.5 and $5.2^{\circ} 2 \mathrm{q}$ corresponding to the diffraction planes of the hexagonal MCM-41 structure (Fig. 2B). These results indicate that the use of these three surfactants leads to the formation of MCM-41 with almost identical textural characteristics and suggesting thus that the three molecules $\left[\mathrm{C}_{16} \mathrm{MIm}\right] \mathrm{Cl},\left[\mathrm{C}_{16} \mathrm{MPy}\right] \mathrm{Cl}$ and CTAC exhibit identical templating efficiency under the applied conditions. This finding implies that the three surfactants feature similar interactions in solution permitting them to form micelles during synthesis. Though there exist different theories on the MCM-41 forming mechanism [57] the most accepted one describes the process to rely on a cooperative self-assembly by charged surfactants [58]. Herein the silicate polyanions assemble at the positively charged cationic headgroups of the surfactants due to Coulomb forces. It is this interaction that alters the charge density at the interface, allowing the surfactant to form and to assemble micelles.

\subsection{Mesoporous $Y$ zeolite by ionic liquid based surfactant templating}

In this section we describe the use of the three tensioactive molecules CTAC, $\left[\mathrm{C}_{16} \mathrm{MIm}\right] \mathrm{Cl}$ and $\left[\mathrm{C}_{16} \mathrm{MPy}\right] \mathrm{Cl}$ in the surfactant
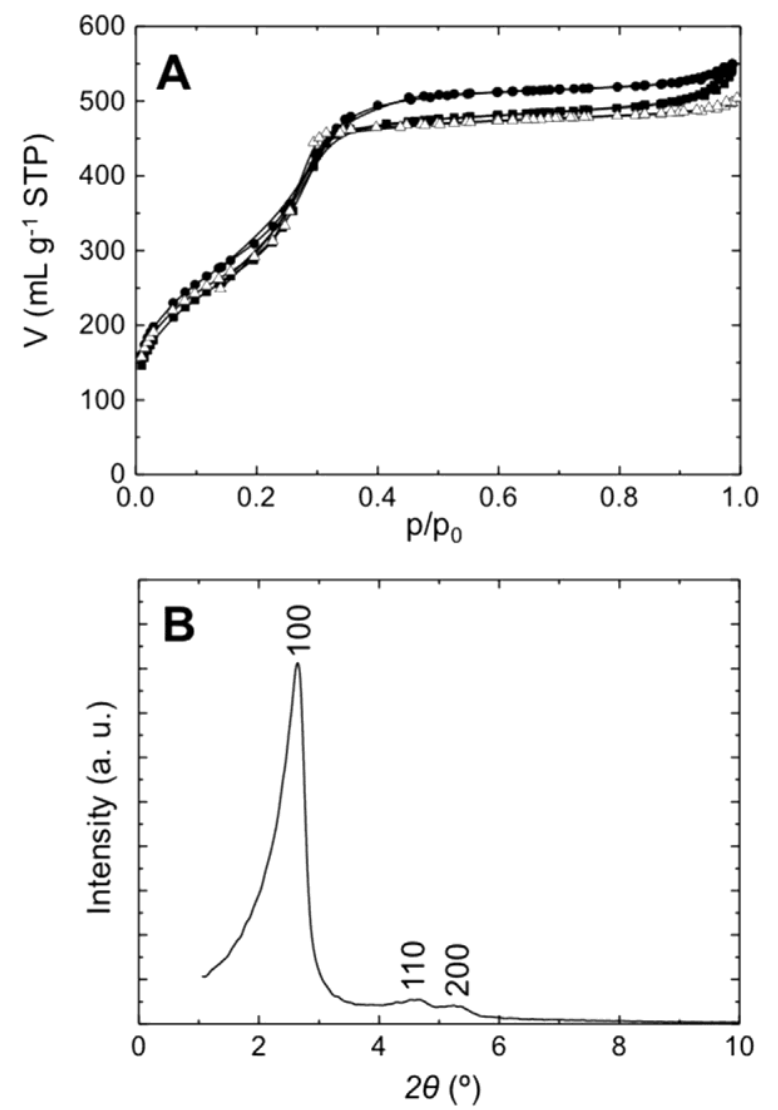

Fig. 2. A: $\mathrm{N}_{2}$ adsorption and desorption isotherms at $77 \mathrm{~K}$ of MCM-41 synthetized with CTAC ( ), $\left[\mathrm{C}_{16} \mathrm{MIm}\right] \mathrm{Cl}(\mathrm{C})$ and $\left[\mathrm{C}_{16} \mathrm{MPy}\right] \mathrm{Cl}(-)$. B: Low angle XRD pattern of MCM-41 synthetized with and $\left[\mathrm{C}_{16} \mathrm{MPy}\right] \mathrm{Cl}$. templating assisted transformation of $\mathrm{Y}$ zeolite. Calcined materials were named HY-TA, HY-MIm, HY-MPy. Additionally, a synthesis without the use of any surfactant was carried out yielding the material $\mathrm{HY}-\mathrm{NaOH}$. The nitrogen adsorption and desorption isotherms show important differences in their shapes for the materials obtained using the different surfactants during the templating process (Fig. 3A). The parent zeolite HY presents a classical type I isotherm with a horizontal hysteresis loop closing at $\mathrm{p} / \mathrm{p}_{0} 1 / 40.42$ due to the tensile strength effect [59] characteristic for inaccessible mesoporosity. A type IV isotherm is achieved for the HY-TA material figuring a sharp nitrogen uptake at $\mathrm{p} / \mathrm{p}_{0} \quad 1 / 40.3 \mathrm{e} 0.4$ indicating a narrow mesopore size distribution with a maximum at $3.2 \mathrm{~nm}$ estimated by the BJH method (Fig. 3C). The equivalent specific surface area amounts to 883 and $837 \mathrm{~m}^{2} \mathrm{~g}^{-1}$ for HY and HY-TA, respectively. These results compare well to those previously reported in the literature [42]. The HY-MIm and HY-MPy materials presents similar surface area $\left(805 \mathrm{~m}^{2} \mathrm{~g}^{-1}\right)$ but with different capillary condensation regimes. Indeed the isotherm obtained for HY-MIm figures a wide hysteresis loop at $\mathrm{p} / \mathrm{p}_{0} 1 / 40.3 \mathrm{e} 0.6$ indicating the formation of mesopores of sizes within 3 and $5 \mathrm{~nm}$. Finally, the HY-MPy material shows even a larger distribution of mesopores (3e12 nm). It should be noted that in the absence of surfactant during the templating process $(\mathrm{HY}-\mathrm{NaOH})$ a nonporous material is obtained. Microporous volumes were deduced by calculating the thickness of the adsorbed nitrogen layer on the surface (t-plot method) and using a correction factor indicated by Galarneau et al. [56] (Fig. 3B). The initial HY zeolite shows a microporous volume of $0.32 \mathrm{~mL} \mathrm{~g}^{-1}$ (the larger mesopores present due to dealumination process performed by the supplier do not influence the $t$-plot curve as these pores are larger than $30 \mathrm{~nm}$ and hence form a linear plot in the t-plot). The microporous volume is comparable for all of the obtained samples using the different surfactants and amounting to $0.22 \mathrm{~mL} \mathrm{~g}^{-1}$. The mesoporous volume is the highest for HY-TA $\left(0.39 \mathrm{~mL} \mathrm{~g}^{-1}\right)$ and decreases for HY-MPy to $0.31 \mathrm{~mL} \mathrm{~g}^{-1}$. It hence seems that the nature of the surfactant influences mostly the mesopore size distribution and mesoporous volume, whilst microporous volume seems to be independent of the employed surfactant in the surfactant templated samples.

The texture of the materials was further investigated by electron microscopy (Fig. 4). The HR-TEM images of the samples obtained through surfactant templating present long-range ordered zeolite crystallinity, observed as long parallel crystallographic planes throughout the material. Within these crystalline planes electron clear domains can be observed ascribable to the mesopores. It is to notice that the HY-MIm material evidences mesopores of more uniformed size (3e5 $\mathrm{nm}$ ) and distribution, whilst the HY-MPy material shows strongly disordered mesopores with larger size distributions (3e12 nm) as already indicated by nitrogen sorption isotherms. The LR-TEM images recorded on thin slices of the crystals show homogeneous distribution of the mesoporosity on the entire section.

The morphology of the materials was investigated by SEM. Fig. 5 evidences that the shape and size of the crystals are comparable for the parent HY zeolite and for the samples obtained through surfactant templating. Crystal sizes are comprised in between of 0.3 and $0.8 \mathrm{~mm}$ for all materials, indicating that morphology is maintained throughout the surfactant templating.

The XRD patterns of the parent zeolite HY and of the rearranged samples are represented in Fig. 6. All of the obtained diffractograms exhibit at wide angles characteristic peaks for the highly crystalline FAU structure with large crystal sizes as indicated by the sharp diffraction peaks. As far as the low angle X-ray pattern is concerned, HY-TA evidences a large peak at $2^{\circ} 2 \eta$ indicating a long-range order of the mesopores. A similar peak is observed for the HY-MIm sample but with less intensity indicating a material with lower 

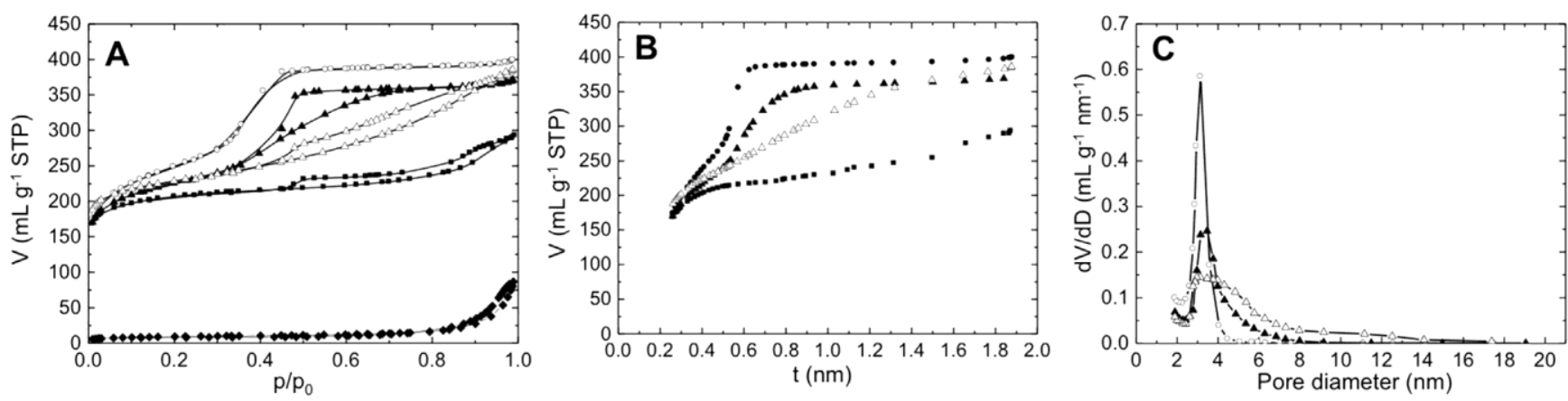

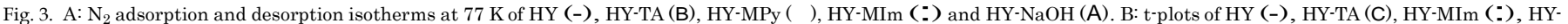
MPy ( ). C: BJH pore size distribution of the adsorption branch of HY-TA (B), HY-MPy ( ) and HY-MIm (:).
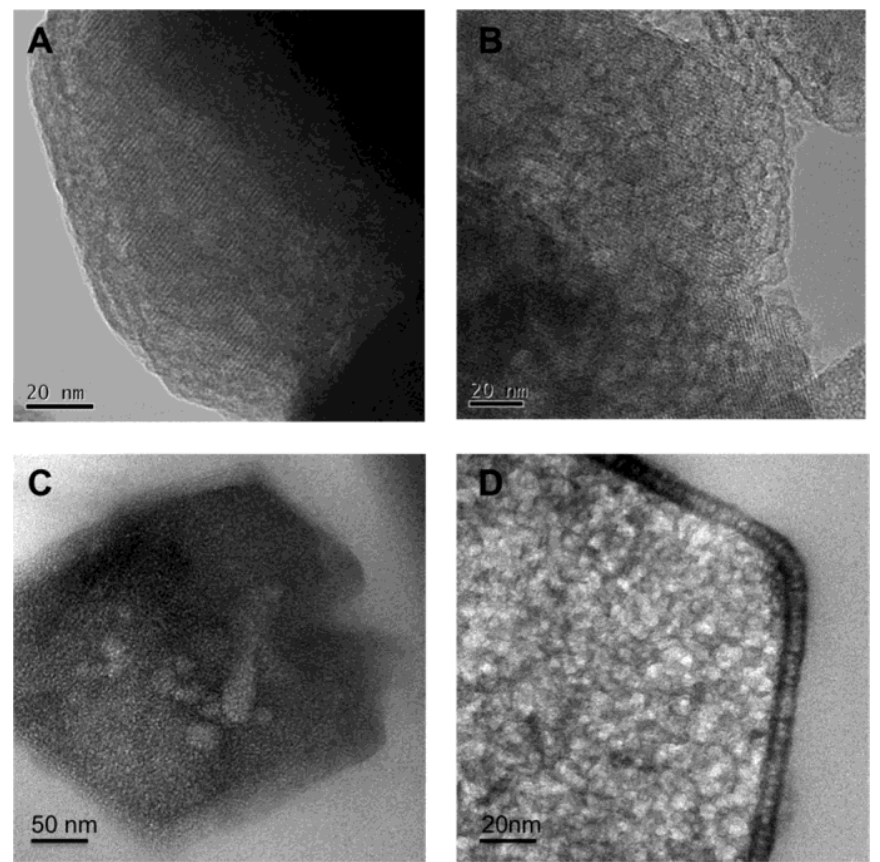

Fig. 4. High resolution TEM images of HY-MIm (A) and HY-MPy (B). Low resolution TEM images of thin slices of HY-MIm (C) and HY-MPy (D).

order of the mesoporosity. Finally, the HY-MPy does not show the presence of any peak in the low angle region as for the parent HY material. These results confirm the observations gained from nitrogen sorption isotherms and from electron microscopy evidencing high organization of mesopores for the HY-TA and HYMIm samples.

As the templating efficiency of all of the surfactants has shown been to be equal in the synthesis of MCM-41, the explanation for their different behavior in surfactant templating of zeolites should lie in the nature of the mechanism of the process. The group of Ivanova has very recently found evidence that such a process involving $\mathrm{CTAB}$ as structure directing agent relies on the following mechanism: i) the treatment with alkali leads to fast destruction of SieOeSi bonds accompanied with rapid desilication and partial exchange of zeolite protons with $\mathrm{Na}^{\mathrm{p}}$ cations followed by the detachment of crystallites and the creation of mesopores inside the crystals $(3 e 20 \mathrm{~nm})$ and in between the crystallites (>30 nm); ii) exchange of the $\mathrm{Na}^{\mathrm{p}}$ with $\mathrm{CTA}^{\mathrm{p}}$ cations results in further exfoliation and segregation of the zeolite crystallites. The CTA $\mathrm{C}^{\mathrm{p}}$ cations form micelles that are responsible for the nucleation of the mesoporous phase inside the zeolite mesopores and on the external surface of the crystallites; iii) by hydrothermal treatment the siliceous species removed from the zeolite structure during desilication condense around the micelles and lead to the formation of a mesoporous phase with uniform mesopores of micelle size $(3 e 4 \mathrm{~nm})[38,39]$. This process has been referred as zeolite recrystallization. A possible explanation for the different behavior of the imidazolium, pyridinium and ammonium salts might be related to the kinetics of cation exchange of the surfactant with $\mathrm{Na}^{\mathrm{p}}$. This would suggest that for the pyridinium cation the exchange may be incomplete leading to non-uniform micelle formation which could explain the wider size distribution of the obtained mesopores upon calcination. Yet, from EDX analysis no traces of $\mathrm{Na}^{\mathrm{p}}$ where found in any of the samples, indicating that the $\mathrm{Na}^{\mathrm{p}} /$ surfactant cation exchange should be complete for all of the obtained materials. Furthermore, the material subjected to the rearrangement conditions in the absence
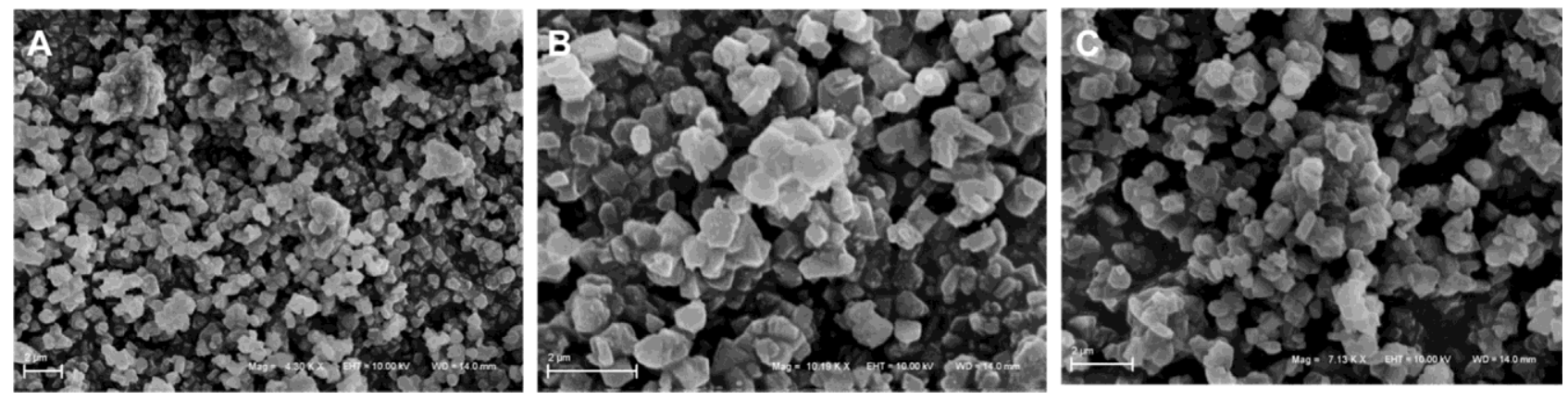

Fig. 5. SEM images of HY (A), HY-MIm (B) and HY-MPy (C) 

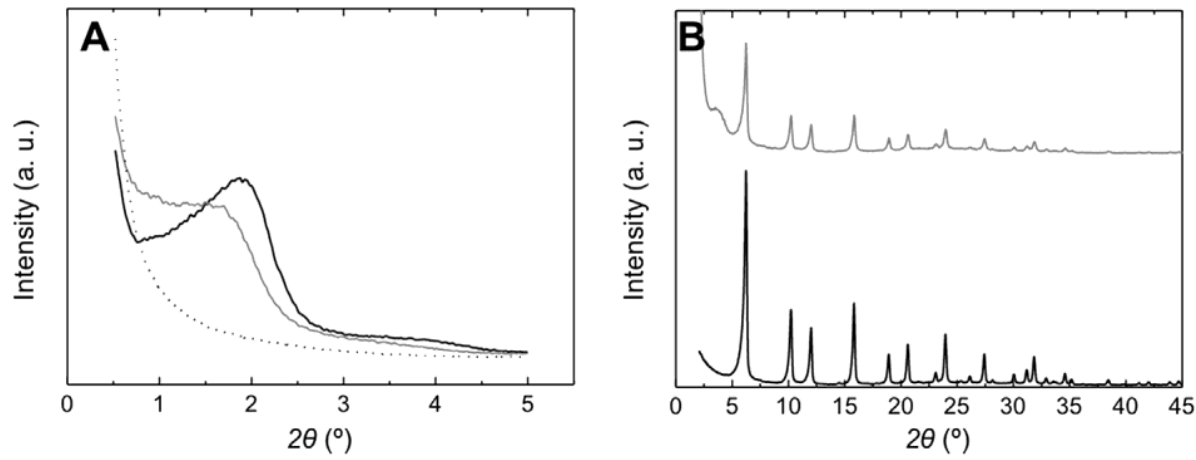

Fig. 6. A: Small angle XRD patterns of HY-TA (black), HY-MIm (grey) and HY-MPy (dotted). B: wide angle XRD patterns of HY (black) and HY-MIm (grey).

of any surfactant (HY-NaOH material) shows high presence of $\mathrm{Na}$ with an $\mathrm{Al} / \mathrm{Na}$ ratio close to 1 (see ESI for EDX results).

As the $\mathrm{Na}$ /surfactant cation exchange takes place for all of the described surfactants this cannot account as consideration for the variations in the textural properties of the surfactant templated samples. A possible explanation may lie in their micelle formation ability of the different surfactants within the confined spaces of the zeolite crystals after cation exchange. This would suggest that the $\mathrm{MPy}^{\mathrm{p}}$ cation is less prone to form ordered micelles after cation exchange and thus leading to a less defined porosity after calcination. These results thus strongly suggest that the described surfactant templating approach relies more on a truly zeolite rearrangement process as stipulated by the group of GarciaMartinez [40,41], and less on a dissolution-recrystallization process. Notwithstanding, further insights are necessary to determine the exact nature for the different templating behavior of these structural directing agents when used in surfactant templating of zeolites.

The acidity of the samples was investigated by temperature programmed desorption of ammonia. The parent HY zeolite shows two peaks in the TPD profile (Fig. 7A). A minor centered at $170^{\circ} \mathrm{C}$ corresponding to weaker acid sites and a broader, more intense peak at $320{ }^{\circ} \mathrm{C}$ ascribable to the desorption of ammonia from stronger acid sites. The TPD- $\mathrm{NH}_{3}$ profiles of the surfactant templated samples are very similar and rather a single very large peak is recorded centered at around $250 \mathrm{e} 300^{\circ} \mathrm{C}$. By comparing the TPD$\mathrm{NH}_{3}$ profiles of the parent zeolite $\mathrm{HY}$ with the mesoporous zeolites a slight decrease of the stronger acid sites can be deduced. The overall acidity was calculated by integrating the area under the curves. For the zeolite HY an acidity of $0.67 \mathrm{mmol} \mathrm{g}^{-1}$ was obtained, while for the mesoporous zeolites the acidity is slightly lower and comprised between 0.51 and $0.41 \mathrm{mmol} \mathrm{g}^{-1}$ (Table 1). This indicates that the surfactant templating process weakens the acid sites, explainable by the reduction in crystallinity for these materials. A Si/Al ratio of 15 was found for all of the materials, which strongly indicates that no overall desilication occurs during the treatment.

The nature of the acid sites was further investigated by the adsorption of pyridine followed by Fourier Transform Infra Read Spectroscopy (FTIR) (Fig. 7B). The parent zeolite exhibits a majority of Brønsted acid sites $\left(1544 \mathrm{~cm}^{-1}\right)$ with a smaller amount of Lewis acidity $\left(1455 \mathrm{~cm}^{-1}\right)$ [60]. The zeolites after surfactant templating show the presence of Brønsted acid and Lewis acid sites, which could indicate the formation of some extra framework silica alumina species within the material. This property seems attracting from a catalytic point of view where different acid sites could widen the applicability of the materials.

\section{Conclusions}

In summary, imidazolium and pyridinium ionic liquids where used in the synthesis of siliceous MCM-41 and in the surfactant templating of $\mathrm{Y}$ zeolite. Textural properties of these materials were compared to those obtained with the classical used ammonium based surfactant (CTAC). We found that these surfactants present identical templating efficiency in the formation of MCM-41. Yet, in the formation of mesoporous $\mathrm{Y}$ zeolite their templating efficiency differs importantly. Y zeolite with narrow, less narrow and wide mesopore size distributions were achieved for the surfactants CTAC, $\left[\mathrm{C}_{16} \mathrm{MIm}\right] \mathrm{Cl}$ and $\left[\mathrm{C}_{16} \mathrm{MPy}\right] \mathrm{Cl}$, respectively. These results strongly suggest that the micellization ability of these surfactants is similar in solution as in the synthesis of MCM-41 but alters importantly in the confined zeolite spaces during the surfactant assisted transformation and indicates that the mechanism of this transformation relies on a zeolite rearrangement process. These results are furthermore crucial from a catalytic point of view as
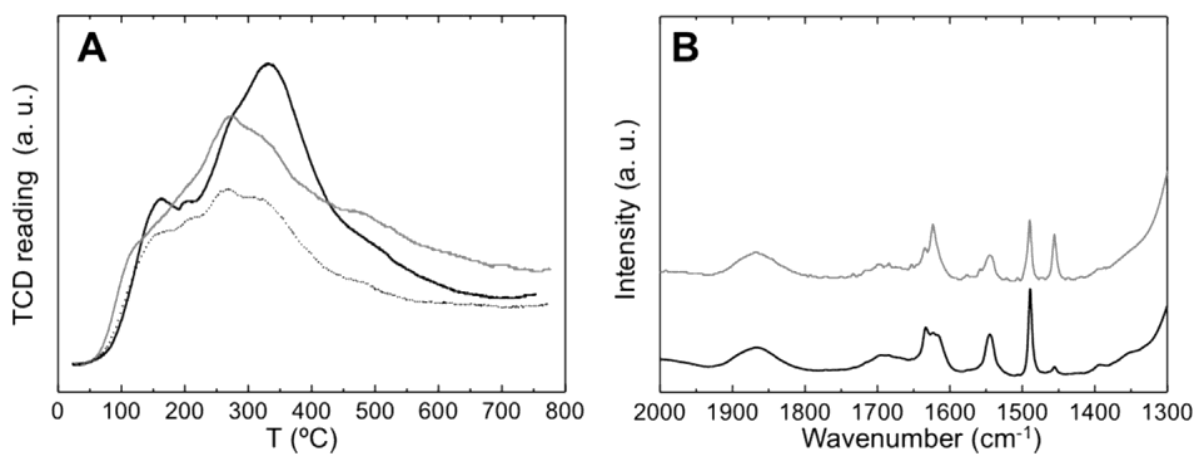

Fig. 7. A: TPD-NH $\mathrm{NH}_{3}$ of HY (black), HY-TA (grey) and HY-MPy (dotted). B: FTIR of pyridine adsorbed on HY (black) and HY-MIm (grey). 
Table 1

Textural and acidic properties of parent zeolite HY and rearranged materials HY-TA, HY-MIm and HY-MPy.

\begin{tabular}{|c|c|c|c|c|}
\hline Sample & $\mathrm{S}_{\mathrm{BET}}\left(\mathrm{m}^{2} \$ \mathrm{~g}^{-1}\right)$ & $\mathrm{V}_{\text {meso }}\left(\mathrm{mL} \$ \mathrm{~g}^{-1}\right)$ & $\mathrm{V}_{\text {micro }}\left(\mathrm{mL} \$ \mathrm{~g}^{-1}\right)$ & Acidity $\left(\mathrm{mmol} \$ \mathrm{~g}^{-1}\right)$ \\
\hline HY & 837 & e & 0.32 & 0.67 \\
\hline HY-TA & 883 & 0.39 & 0.21 & 0.51 \\
\hline HY-MIm & 802 & 0.33 & 0.22 & 0.47 \\
\hline HY-MPy & 807 & 0.31 & 0.22 & 0.41 \\
\hline
\end{tabular}

mesopores of different length scales can importantly alter product distribution and mass transfer issues for a given reaction. We are currently investigating the catalytic activity of these hierarchically porous zeolites.

\section{Acknowledgments}

This work was supported by CAPES through a Young Talent Award (058/2012). Authors thank Otelo J. Machado for DRX analysis and the CNANO facility for TEM images.

\section{References}

[1] W.-H. Chen, Q. Zhao, H.-P. Lin, Y.-S. Yang, C.-Y. Mou, S.-B. Liu, Microporous Mesoporous Mater. 66 (2003) $209 \mathrm{e} 218$.

[2] K. Suzuki, Y. Aoyagi, N. Katada, M. Choi, R. Ryoo, M. Niwa, Catal. Today 132 (2008) $38 \mathrm{e} 45$

[3] J. Aguado, J.L. Sotelo, D.P. Serrano, J.A. Calles, J.M. Escola, Energy Fuels 11 (1997) $1225 \mathrm{e} 1231$

[4] J.C. Groen, W. Zhu, S. Brouwer, S.J. Huynink, F. Kapteijn, J.A. Moulijn, J. P'erezRamírez, J. Am. Chem. Soc. 129 (2007) 355.

[5] L. Gueudré, M. Milina, S. Mitchell, J. P’erez-Ramírez, Adv. Mater. 24 (2014) $209 e 219$.

[6] B. Coasne, A. Galarneau, C. Gerardin, F. Fajula, F. Villemot, Langmuir 29 (2013) $7864 \mathrm{e} 7875$.

[7] C.-C. Chang, A.R. Teixeira, C. Li, P.J. Dauenhauer, W. Fan, Langmuir 29 (2013) $13943 \mathrm{e} 13950$.

[8] L.-H. Chen, X.-Y. Li, J.C. Rooke, Y.-H. Zhang, X.-Y. Yang, Y. Tang, F.-S. Xiao, B.L. Su, J. Mater. Chem. 22 (2012) 17381e17403.

[9] K. Sadowska, K. Gora-Marek, J. Datka, J. Phys. Chem. C 117 (2013) 9237e9244.

[10] A. Khodakov, A. Griboval-Constant, R. Bechara, V.L. Zholobenko, J. Catal. 206 (2002) 230e241.

[11] G.-G. Park, T.-H. Yang, Y.-G. Yoon, W.-Y. Lee, C.-S. Kim, Int. J. Hydrogen Eng. 28 (2003) 645e650.

[12] D. Song, J. Li, J. Mol. Catal. A 247 (2006) $206 e 212$.

[13] M. Iwamoto, Y. Tanaka, N. Sawamura, S. Namba, J. Am. Chem. Soc. 125 (2003) $13032 \mathrm{e} 13033$

[15] J. P'erez-Ramírez, C.H. Christensen, K. Egeblad, C.H. Christensend, J.C. Groen, Chem. Soc. Rev. 37 (2008) 2530e2542.

[16] R. Chal, C. Gerardin, M. Bulut, S. van Donk, ChemCatChem 3 (2011) 67e81.

[17] S. Lopez-Orozco, A. Inayat, A. Schwab, T. Selvam, W. Schwieger, Adv. Mater. 23 (2011) 2602e2615.

[18] K. Egeblad, C.H. Christensen, M. Kustova, C.H. Christensen, Chem. Mater. 20 (2008) 946e960.

[19] W.J. Roth, P. Nachtigall, R.E. Morris, J. ejka, Chem. Rev. 114 (2014) $4807 e 4837$.

[20] D.P. Serrano, J.M. Escola, P. Pizarro, Chem. Soc. Rev. 42 (2013) 4004 e4035.

[21] S. van Donk, A.H. Janssen, J.H. Bitter, K.P. de Jong, Catal. Rev. Sci. Eng. 45 (2003) $297 e 319$.

[22] Y. Hong, J.J. Fripiat, Microporous Mater. 4 (1995) $323 e 334$.
[23] S. Moreno, G. Poncelet, Microporous Mater. 12 (1997) $197 e 222$.

[24] J. Lynch, F. Raatz, P. Dufresne, Zeolites 7 (1987) $333 e 340$.

[25] A.H. Janssen, A.J. Koster, K.P. de Jong, Angew. Chem. Int. Ed. 40 (2001) $1102 e 1104$.

[26] X. Li, R. Prins, J.A. van Bokhoven, J. Catal. 262 (2009) $257 e 265$.

[27] Y. Tao, H. Kanoh, L. Abrams, K. Kaneko, Chem. Rev. 106 (2006) 896e910.

[28] L. Wangb, Z. Zhangb, C. Yinb, Z. Shanb, F.-S. Xiao, Microporous Mesoporous Mater. 131 (2010) 58e67.

[29] I. Schmidt, A. Boisen, E. Gustavsson, K. Ståhl, S. Pehrson, S. Dahl, A. Carlsson, C.J.H. Jacobsen, Chem. Mater. 13 (2001) 4416e4418.

[30] F.N. Gu, F. Wei, J.Y. Yang, N. Lin, W.G. Lin, Y. Wang, J.H. Zhu, Chem. Mater. 22 (2010) $2442 \mathrm{e} 2450$.

[31] J. Kim, C. Jo, S. Lee, R. Ryoo, J. Mater. Chem. A 2 (2014) $11905 e 11912$.

[32] M. Kustova, K. Egeblad, K. Zhu, C.H. Christensen, Chem. Mater. 19 (2007) 2915 e2917.

[33] D. Nandan, S.K. Saxena, N. Viswanadham, J. Mater. Chem. A 2 (2014) $1054 \mathrm{e} 1059$.

[34] B.T. Holland, L. Abrams, A. Stein, J. Am. Chem. Soc. 121 (1999) 4308e4309.

[35] C. Madsen, C.J.H. Jacobsen, Chem. Commun. (1999) $673 e 674$.

[36] D. Verboekend, M. Milina, S. Mitchell, J. P’erez-Ramírez, Cryst. Growth \& Des. 13 (2013) 5025e5035.

[37] I.I. Ivanova, E.E. Knyazeva, Chem. Soc. Rev. 42 (2013) 3671e3688.

[38] I.A. Kasyanov, A.A. Maerle, I.I. Ivanova, V.I. Zaikovskii, J. Mater. Chem. A 2 (2014) $16978 \mathrm{e} 16988$.

[39] I.I. Ivanova, B.A. Kasyanova, A.A. Maerlea, V.I. Zaikovskiic, Microporous Mesoporous Mater. 189 (2014) $163 e 172$.

[40] T. Prasomsri, W. Jiao, S.Z. Weng, J. Garcia Martinez, Chem. Commun. 51 (2015) $8900 e 8911$.

[41] J. Garcia-Martinez, C. Xiao, K.A. Cychosz, K. Li, W. Wan, X. Zou, M. Thommes, ChemCatChem 6 (2014) 3110e3115.

[42] R. Chal, T. Cacciaguerra, S. van Donk, C. G'erardin, Chem. Commun. 46 (2010) $7840 \mathrm{e} 7842$.

[43] I.I. Ivanova, A.S. Kuznetsov, V.V. Yuschenko, E.E. Knyazeva, Pure Appl. Chem. 76 (2004) 1647e1658.

[44] V.V. Ordomsky, V.Y. Murzin, Y.V. Monakhova, Y.V. Zubavichus, E.E. Knyazeva, N.S. Nesterenko, I.I. Ivanova, Microporous Mesoporous Mater. 105 (2007) $101 e 110$.

[45] Y. Goto, Y. Fukushima, P. Ratu, Y. Imada, Y. Kubota, Y. Sugi, M. Ogura, M. Matsukata, J. Por. Mater. 9 (2002) $43 \mathrm{e} 48$.

[46] R. Giernoth, Angew. Chem. Int. Ed. 49 (2010) 2834 e2839.

[47] Z. Li, Z. Jia, Y. Luan, T. Mu, Curr. Opin. Solid State Mater. Sci. 12 (2008) 1 e8.

[48] Z. Ma, J. Yu, S. Dai, Adv. Mater. 22 (2010) 261.

[49] M.L. Mignoni, M.O. De Souza, S.B.C. Pergher, R.F. De Souza, K. BernardoGusmão, Appl. Catal. A 374 (2010) 26e30.

[50] J.M.M. Blanes, B.M. Szyja, F. Romero-Sarria, M. Centeno, E.J.M. Hensen, J.A. Odriozola, S. Ivanova, Chem. Eur. J. 19 (2013) $2122 \mathrm{e} 2130$.

[51] T. Wang, H. Kaper, M. Antonietti, B. Smarsly, Langmuir 23 (2007) 1489e1495.

[52] A. Sachse, C. Wuttke, E. Lissner, M.O. de Souza, Chem. Eur. J. 20 (2014) $14996 \mathrm{e} 14999$.

[53] S. Brunauer, P.H. Emmett, E. Teller, J. Am. Chem. Soc. 60 (1938) $309 e 319$.

[54] F. Rouquerol, J. Rouquerol, K. Sing, Adsorption by Powders \& Solids, Academic Press, 1999.

[56] A. Galarneau, F. Villemot, J. Rodriguez, F. Fajula, B. Coasne, Langmuir 30 (2014) $13266 \mathrm{e} 13274$.

[57] L. Jin, S.M. Auerbach, P.A. Monson, Langmuir 29 (2013) 766e780.

[58] Y. Wan, D. Zhao, Chem. Rev. 107 (2007) 2821e2860.

[59] J.C. Groen, L.A.A. Peffer, J. P'erez-Ramirez, Microporous Mesoporous Mater. 60 (2003) 1 e17.

[60] C.A. Emeis, J. Catal. 141 (1993) 347e354. 